\title{
Relação do nível de sombreamento artificial e da adubação sobre o desenvolvimento da forrageira Urochloa brizantha cv. Marandu
}

\author{
Relation of shading level and Fertilization on the development of "Urochloa brizantha" \\ cv. Marandu
}

\author{
MARTINS, Athila Damasceno ${ }^{1 *}$; SOUSA, Luciano Fernandes ${ }^{1}$; NÓBREGA, Eucivan \\ Bento da ${ }^{1}$; DONIZETTI, José Geraldo dos Santos ${ }^{1}$; SANTOS, Antonio Clementino \\ $\operatorname{dos}^{1}$; SOUSA, Jhone Tallison Lira de ${ }^{1}$
}

\footnotetext{
${ }^{1}$ Universidade Federal do Tocantins Araguaína, Tocantins, Brasil.

*Endereço para correspondência: athilazoot@hotmail.com
}

\section{RESUMO}

O estudo foi realizado na Universidade Federal do Tocantins (UFT), na Escola de Medicina Veterinária e Zootecnias, Campus de Araguaína, foram avaliadas as características morfogênicas, agronômicas e o índice de área foliar da Urochloa brizantha cv. Marandu, submetido a crescentes níveis de sombreamento artificial com e sem adubação, sendo os níveis de sombreamento $(0 \%$; $30 \% ; 50 \%$ e $70 \%)$ e adubação de (80 $\mathrm{kg} \mathrm{ha}^{-1}$ ano). $\mathrm{O}$ solo onde a forragem encontrava-se implantada era o Neossolo Quartizarênico Órtico típico. Tendo em vista a necessidade de mais conhecimento sobre os sistemas Silvipastoris na região Norte do país, o objetivo deste trabalho foi investigar as mudanças morfológicas ocorrida pelo vegetal através do estudo da morfogênese e de como a adubação atua nesse processo, o delineamento experimental foi em blocos casualizados (DBC), em arranjo fatorial $4 \times 2$. O sombreamento aumentou, comprimento de bainha (CB) e consequentemente no comprimento médio de lâmina foliar aparecida (CMLFAP) e adubação conferiu influências na duração de vida de folha (DVF), CB, taxa de alongamento de colmo (TALC), número de folhas mortas (NFM). A produtividade em $\mathrm{kg}$ de matéria seca não foram alterados pelos tratamentos e não alterou de forma significativa a taxa de senescência foliar (TSF). A Urochloa brizantha cv. Marandu mostrou capacidade de adaptação aos níveis crescentes de sombreamento, sendo capaz de produzir um percentual de matéria seca (MS) considerável em comparação ao sol pleno, ambos implantados em solo arenoso.

Palavras-chave: características morfogênicas, marandu, sombreamento

\section{SUMMARY}

The study was conducted at the Federal University of Tocantins, in the School of Veterinary Medicine and Zootecnias, Campus Araguaína were evaluated morphogenetic, agronomic and leaf area index of Urochloa brizantha characteristics. Palisade, subjected to increasing levels of shading with and without fertilizer, and shading levels $(0 \%, 30 \%, 50 \%$ and $70 \%)$ and fertilization $\left(80 \mathrm{~kg} \mathrm{ha}^{-1}\right.$ year). The soil where the forage found himself deployed was Quartzarenic Neosol typical Orthic. Given the need for more knowledge about the silvopastoral systems in Northern region the objective was to investigate the morphological changes that occurred by plant through the study of morphogenesis and acts as a fertilizer in this process, the experimental design was a randomized block (DBC) in factorial arrangement $2 \times 2$, shading increased the $\mathrm{CB}$ and consequently on CMLFAP fertilization and gave influences on DVF, CB, TALC, NFM. Productivity in $\mathrm{Kg}$ dry matter not affected by treatments. The Urochloa brizantha. Marandu showed ability to adapt to increasing levels of shading, being able to produce a considerable percentage of MS compared to full sun both deployed in sandy soil.

Keywords: morphogenesis, marandu, shading 


\section{INTRODUÇÃO}

O manejo inadequado da forragem causa uma redução na produtividade de biomassa, provocando redução no vigor da planta e, em muitos casos, levando à degradação da forragem (BARBOSA, 2002). Isso acarreta em uma série de percas econômica, pois, com a redução no vigor da planta, sua rebrota é comprometida e não se faz de forma eficiente, em longo prazo causa degradação e, ao longo dos anos, a lotação de animais nas áreas tende a reduzir.

Não bastasse o manejo inadequado, a região do ecótono cerrado-amazônia do país apresenta ao longo do ano uma estação com escassez de chuvas por volta de 180 dias, reduzindo ainda mais a produção de forragem por falta de água no solo, além da grande parte da pecuária está alocada em solo com baixa fertilidade (SANTOS et al., 2011) No entanto, o cenário mundial tem passado por mudanças, onde não basta apenas produzir; a cada dia, o consumidor cobra mais qualidade maior sustentabilidade com reduções dos impactos ambientais. Mediante esse cenário, surge uma alternativa promissora que são os sistemas integrados de produção que permitam um melhor aproveitamento das áreas e ainda proporcione uma produção satisfatória. Com isso, surgem os sistemas silvipastoris (Ssp's), uma alternativa que consorcia árvores ou arbustos e capim, onde os benefícios propiciados por estes sistemas são inúmeros como exemplo os listados por Pagiola et al. (2004), como conservação dos recursos hídricos, a conservação do solo, o aumento da biodiversidade e o aumento do sequestro de carbono. Porém, o conhecimento que se tem sobre esse sistema para a região precisa ser estudado mais a fundo, uma vez que plantas que estão em ambiente sombreado buscam adequações fisiológicas podendo ser tanto fisiológicas como morfológicas. (MOREIRA et al., 2009) A morfogênese é uma ferramenta que, segundo Alexandrino et al. (2004), permite identificar o comportamento da gramínea de acordo o manejo empregado.

Baseado nesta necessidade de informações sobre os Sistemas Silvipastoril Ssp's, tendo em vista seu alto custo de implantação, foi realizado um ensaio com sombreamento artificial, este estudo tem como objetivo investigar as mudanças morfológicas ocorridas pela Uroclhoa brizanta cv. Marandu através do estudo da morfogênese e de como a adubação atua nesse processo.

\section{MATERIAIS E MÉTODOS}

$\mathrm{O}$ ensaio foi realizado de janeiro a abril de 2013, foram avaliados quatro níveis de sombreamento artificial com lâmina sombreadora de nylon, de diferentes granulométrias e dois níveis de adubação (com e sem adubação), na forrageira Urochloa brizantha $\mathrm{cv}$. Marandu. As parcelas tinham as dimensões de $4 \mathrm{~m}$ comprimento por 1,5 $\mathrm{m}$ de largura, com uma distância $0,60 \mathrm{~m}$ entre parcelas e $1 \mathrm{~m}$ entre blocos. Os tratamentos foram: sol pleno ou testemunha com $0 \%, 30 \%, 50 \%$ e $70 \%$ de sombreamento artificial por malhas de nylon vendidas comercialmente, e dois níveis de adubação (com adubação e sem adubação), sendo que os tratamentos que receberam adubação foram de $80 \mathrm{~kg}$ ha. ano $^{-1}$ de nitrogênio $(\mathrm{N})$ e potássio $\left(\mathrm{K}_{2} \mathrm{O}\right)$, utilizando como fonte o formulado $20-0-20$ e $80 \mathrm{~kg}$ ha . ano $^{-1}$ de fósforo (P) em uma única aplicação, sendo este utilizado o super fosfato simples $\left(\mathrm{P}_{2} \mathrm{O}_{5}\right)$. 
O solo foi classificado como Neossolo Quartizarênico Órtico típico (EMBRAPA, 2006), em que as características químicas e físicas estão descritas na Tabela 1.

As temperaturas, no decorrer de todo o ensaio, mostraram-se sem muitas variações (Figura 1). Para precipitação pluviométrica acumulada no período experimental, os meses que tiveram maiores incidências de chuvas em milímetro foram de janeiro e março, mediante a baixa variação dos dados climáticos, foi assumida no decorrer do processamento dos dados a utilização das médias do ensaio (Figura 2).

Tabela 1. Características químicas e físicas do solo da área experimental nas diferentes profundidades

\begin{tabular}{cccccccccccc}
\hline \multirow{2}{*}{$\begin{array}{l}\text { Prof } \\
\mathrm{cm}\end{array}$} & $\mathrm{pH}$ & $\mathrm{P}$ & $\mathrm{K}$ & $\mathrm{Ca}$ & $\mathrm{Mg}$ & $\mathrm{Al}$ & $\mathrm{H}+\mathrm{Al}$ & \multicolumn{3}{c}{ Textura } & \multirow{2}{*}{$\mathrm{CT}$} \\
\cline { 2 - 12 } & $\mathrm{Ca} \mathrm{Cl}^{-2}$ & $\mathrm{mg} \mathrm{dm}^{-3}$ & \multicolumn{4}{c}{$\mathrm{cmol} \mathrm{dm}^{-3}$} & & Areia & Silte & Argila & \\
\hline $0-10$ & 4,57 & 0,98 & 0,026 & 1,18 & 0,38 & 0,28 & 2,84 & 92,1 & 4,3 & 3,6 & Areia \\
$10-20$ & 4,18 & 0,51 & 0,027 & 0,35 & 0,23 & 0,41 & 2,58 & 92,4 & 4,1 & 3,5 & Areia \\
$20-30$ & 4,15 & 0,41 & 0,027 & 0,19 & 0,31 & 0,56 & 2,74 & 94,0 & 3,6 & 2,4 & Areia \\
\hline
\end{tabular}

CT = Classificação textural.

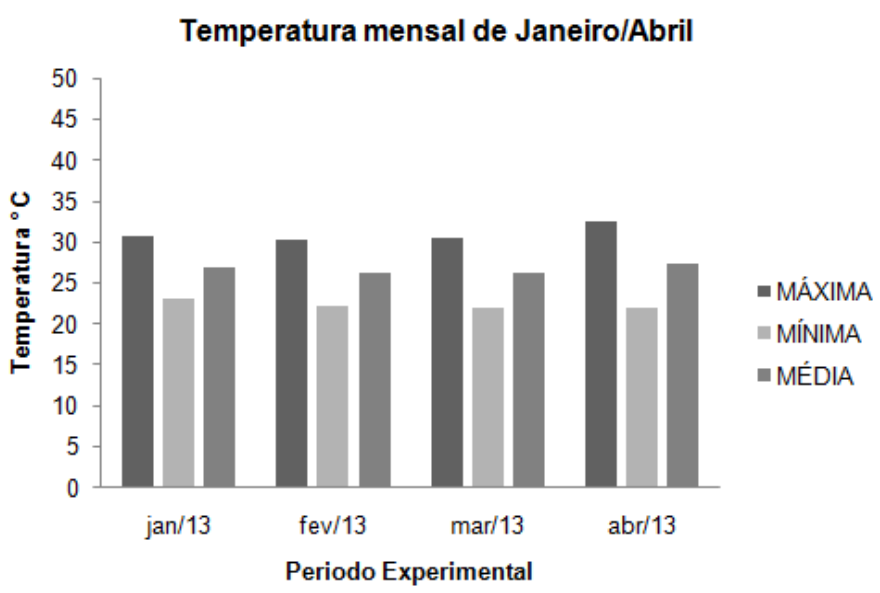

Figura 1. Temperatura mensal do período experimental

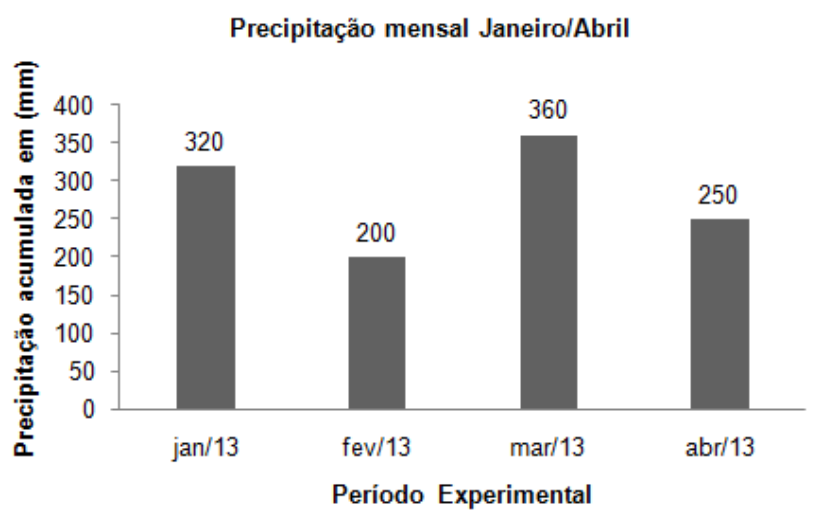

Figura 2. Precipitação acumulada mensal do período experimental 
Durante 30 dias correspondentes ao período de descanso da forrageira, realizaram-se avaliações morfogênicas a cada sete dias, para os quais quantificou-se o número de folhas expandidas por perfilho, o crescimento do capim-brachiária (Urochloa brizantha cv. Marandu). Foram registrados o aparecimento, $\mathrm{O}$ comprimento de segmentos verde e/ou senescente de lâminas foliares, conforme Davies (1993) e o de alongamento de colmos, a fim de se estimar as taxas de alongamento foliar (TAlF), taxa de alongamento de colmo (TAlC), taxa de senescência foliar TSF. Taxa de aparecimento de perfilho (perfilho surgido. perfilho existente ${ }^{-1}$. dia): relação entre o número de perfilhos surgidos pelo número de perfilhos existentes e o número de dias do ciclo.

Comprimento final da lâmina foliar $(\mathrm{CFiF}, \mathrm{cm})$ : comprimento final médio de todas as folhas expandidas do perfilho.

Duração de vida de folha (DVF, dias): estimada pela equação de Lemaire \& Chapman (1996): DVF $=N F V$ Filocrono.

Dois dias após o corte foram marcadas três touceiras em cada parcela (12 por tratamento), alterando com novas touceiras a cada novo ciclo. Em cada uma das touceiras, quatro perfilhos foram identificados aleatoriamente com anéis coloridos. Nos referidos perfilhos, determinou-se a cada sete dias o comprimento total e da porção verde, de todas as lâminas foliares que não estavam completamente mortas, a partir da lígula da própria folha - quando já estava expandida, ou da lígula da folha mais recentemente expandida, em se tratando de folha emergente.

O comprimento da porção senescente foi obtido pela diferença entre $o$ comprimento total da lâmina foliar e da sua porção ainda verde. Estimou-se, ainda, o alongamento do colmo, como a diferença de altura da lígula mais alta da base do perfilho por ocasião da primeira e última leitura, durante o período de descanso.

Foi contabilizado o número de perfilhos por unidade de área, contando-se o número de perfilhos da área de um quadrado de metal com $0,15 \mathrm{~m}^{2}$. Estimou-se também a taxa de acúmulo de forragem (TAF) durante o período de descanso, a partir das taxas de alongamento (TAlF) e senescência (TSF) de lâmina foliar, da taxa de alongamento das hastes (TALH) e da densidade populacional de perfilhos (DPP), conforme a equação:

$$
\mathrm{TAF}=\{[(\text { TalF } \mathrm{x} \text { a1 })-(\mathrm{TSF} \times \mathrm{a} 2)]+(\text { TalH } \mathrm{x} \text { b) }\} \times \mathrm{DPP}
$$

Em que,

$\mathrm{TAFi}$ = taxa de acúmulo de forragem durante o período de descanso $(\mathrm{kg}$ MS/ha);

TAlF = taxa de alongamento de lâmina foliar ( $\mathrm{cm} /$ dia x perfilho);

a1 = índice de peso por unidade de comprimento para lâmina foliar emergente $(\mathrm{g} / \mathrm{cm})$;

TSF = taxa de senescência de lâmina foliar ( $\mathrm{cm} /$ dia x perfilho); $\mathrm{a} 2$ = índice de peso por unidade de comprimento para lâmina foliar adulta $(\mathrm{g} / \mathrm{cm})$;

$\mathrm{TAlH}=$ taxa de alongamento do colmo (cm/dia x perfilho);

$\mathrm{b}=$ índice de peso por unidade de comprimento para colmo $(\mathrm{g} / \mathrm{cm})$;

$\mathrm{DPP}=$ densidade populacional de perfilhos no início do período de descanso (perfilhos/ha). 
A altura do dossel foi estimada através da medição da altura em cinco pontos por meio de régua graduada; a disponibilidade de forragem verde e a relação folha/colmo foram estimadas cortando-se, em cada parcela, uma mostra de $0,25 \mathrm{~m}^{2}$ a $20 \mathrm{~cm}$ do solo a fim de simular a parte colhível pelos animais. Foi separado o material vivo do material morto e em seguida as lâminas foliares dos colmos do material vivo, os quais foram secos em estufa de ventilação forçada a $65^{\circ} \mathrm{C}$ e pesados e o acúmulo de forragem também foi calculado subtraindo-se da disponibilidade de forragem verde ao final do período de descanso.

Análise da estrutura do capimbrachiária (Urochloa brizantha cv. Marandu) foi submetido a quatro níveis de sombreamento e dois níveis de adubação.

O delineamento experimental adotado foi em blocos casualizados em arranjo fatorial. Fator 1: níveis de sombreamento $(0 \%$; 30\%; $50 \%$; e $70 \%)$ e fator 2 : adubação (sem adubação e $80 \mathrm{~kg} \cdot \mathrm{ha}^{-1}$. ano $^{-1}$ de $\mathrm{N}, \quad \mathrm{P}$ e $\mathrm{K}_{2} \mathrm{O}$ ). Os dados foram submetidos aos testes de normalidade (SHAPIRO \& WILK, 1965) e homocedasticidade. (BARTLETT, 1937; COCHRAN, 1941) Para variáveis que apresentaram dados normais e com variâncias homogêneas realizou-se uma analise de variância seguida de regressão para os níveis de sombreamento e de teste de comparação de médias "t-student" para as adubações com nível de $5 \%$ de probabilidade de erro tipo I, para as variáveis que não se encontraram em normalidade foi feita uma transformação logarítmica (Log (x + 1)) e os mesmos procedimentos supracitados.

O modelo estatístico adotado foi:

$Y_{i j k}=\mu+S_{i}+A_{j}+A S_{j i}+B_{k}+e_{i j k}$ em que:

" $\mu$ " é a média geral.
" $\mathrm{S}_{\mathrm{i}}$ " é o efeito do nível de sombreamento $\mathrm{i}, \mathrm{i}=0,30,50$ e 70 .

" $A_{\mathrm{j}}$ " é o efeito da adubação $\mathrm{j}, \mathrm{j}=1$ e 2 (sem e com adubação).

" $S A_{i j}$ " é o efeito da interação do nível de sombreamento $v s$. adubação.

" $\mathrm{B}_{\mathrm{k}}$ " é o efeito do Bloco $\mathrm{k}, \mathrm{k}=1,2$ e 3. " $\mathrm{e}_{\mathrm{ijk}}$ " é o erro.

\section{RESULTADOS E DISCUSSÃO}

Avaliando o número de folhas totais (NFT), observou-se que os tratamentos não exerceram influencia significativa $(\mathrm{P}>0,05)$ para esta variável, embora $\mathrm{o}$ sombreamento parecer retardar $\mathrm{O}$ crescimento e aparecimento de novas folhas, não foi constatado diferenças entre os tratamentos (NFT, NFM e CB), mostrando que a planta preconizou, mesmo em situação de pouca incidência de luz, o seu arranjo estrutural com média de cinco folhas por perfilho (Tabela 2) Componentes da morfogênese da forrageira Urochloa brizantha cv. Marandu).

Quando se comparou o $\mathrm{CB}$ em centímetros, notou-se significância $(\mathrm{P}>0,05)$ tanto para adubação quanto para o sombreamento, apesar de não se constatar interação entre os fatores. A adubação possibilitou maiores médias de comprimento de bainha, isso está ligado à maior TALC, já que as maiores médias de alongamento de bainha se deram nas plantas submetidas aos níveis mais intensos de sombra e adubadas. Esse comportamento da planta é esperado, uma vez que, em situações de estresse por deficiência na qualidade luminosa que chega ao dossel forrageiro, a planta tende a alongar seus colmos, para proporcionar um maior espaçamento entre folhas e garantir uma maior eficiência de entrada de luz para as regiões basais (PACIOLLO et al., 2008) 
Rev. Bras. Saúde Prod. Anim., Salvador, v.15, n.4, p.994-1005 out./dez., 2014 http://www.rbspa.ufba.br ISSN 15199940

Tabela 2. Componentes da morfogênese da forrageira Urochloa brizantha cv. Marandu

\begin{tabular}{|c|c|c|c|c|c|c|c|c|c|}
\hline \multicolumn{10}{|c|}{ Número de folhas totais (NFT dias ${ }^{-1}$ ) } \\
\hline \multirow[b]{2}{*}{ Adubação } & \multicolumn{4}{|c|}{ Sombra $(\%)$} & \multirow[b]{2}{*}{ Médias } & \multicolumn{3}{|c|}{$\mathrm{P}^{*}$} & \multirow{2}{*}{$\begin{array}{l}\mathrm{CV} \\
(\%)\end{array}$} \\
\hline & 0 & 30 & 50 & 70 & & Adub & Somb & $\begin{array}{l}\text { Adub x } \\
\text { Somb }\end{array}$ & \\
\hline Sem adubo $* * 1$ & 5,20 & 5,27 & 5,53 & 5,34 & $5,33^{\mathrm{A}}$ & \multirow{3}{*}{0,87} & \multirow{3}{*}{0,84} & & \multirow{3}{*}{7,96} \\
\hline Com adubo $* * *^{2}$ & 5,22 & 5,32 & 5,32 & 5,36 & $5,30^{\mathrm{A}}$ & & & 0,94 & \\
\hline Médias*****3 & 5,21 & 5,29 & 5,42 & 5,35 & 5,31 & & & & \\
\hline \multicolumn{10}{|c|}{ Número de folhas mortas (NFM mm dia ${ }^{-1}$ ) } \\
\hline & \multicolumn{4}{|c|}{ Sombra $(\%)$} & \multirow[b]{2}{*}{ Médias } & \multicolumn{3}{|c|}{$\mathrm{P}^{*}$} & \multirow{2}{*}{$\begin{array}{l}\mathrm{CV} \\
(\%)\end{array}$} \\
\hline Adubação & 0 & 30 & 50 & 70 & & Adub & Somb & $\begin{array}{l}\text { Adub x } \\
\text { Somb }\end{array}$ & \\
\hline Sem adubo $* *^{4}$ & 0,63 & 0,45 & 0,42 & 0,32 & $0,45^{\mathrm{B}}$ & \multirow{3}{*}{0,016} & \multirow{3}{*}{0,32} & & \multirow{3}{*}{25,21} \\
\hline Com adubo $* * * 5$ & 0,55 & 0,71 & 0,71 & 0,55 & $0,63^{\mathrm{A}}$ & & & 0,17 & \\
\hline Médias****6 & 0,59 & 0,58 & 0,56 & 0,43 & 0,54 & & & & \\
\hline \multicolumn{10}{|c|}{ Número de folhas vivas (NFV mm dia $^{-1}$ ) } \\
\hline & & Sombr & $\mathrm{a}(\%)$ & & & & $\mathrm{P}^{*}$ & & \\
\hline Adubação & 0 & 30 & 50 & 70 & Médias & Adub & Somb & $\begin{array}{l}\text { Adub x } \\
\text { Somb }\end{array}$ & $(\%)$ \\
\hline Sem adubo**? & 4,57 & 4,81 & 5,11 & 5,02 & $4,87^{\mathrm{A}}$ & & & & \\
\hline Com adubo $* * * 8$ & 4,58 & 4,61 & 4,61 & 4,81 & $4,65^{\mathrm{A}}$ & 0,18 & 0,46 & 0,52 & 7,23 \\
\hline Médias $* * * *^{9}$ & 4,57 & 4,71 & 4,86 & 7,91 & 4,76 & & & & \\
\hline & & $\mathrm{Col}$ & mpriment & to de bain & nha $(\mathrm{CB}$ & $\left.\mathrm{cm}^{-1}\right)$ & & & \\
\hline & & Sombr & $\mathrm{a}(\%)$ & & & & $\mathrm{P}^{*}$ & & \\
\hline Adubação & 0 & 30 & 50 & 70 & Médias & Adub & Somb & $\begin{array}{l}\text { Adub x } \\
\text { Somb }\end{array}$ & $(\%)$ \\
\hline Sem adubo $* * 10$ & 21,00 & 24,57 & 24,54 & 24,97 & $23,77^{\mathrm{B}}$ & & & & \\
\hline Com adubo****11 & 20,90 & 33,46 & 33,46 & 29,93 & $29,43^{\mathrm{A}}$ & 0,002 & 0,006 & 0,17 & 14,06 \\
\hline Médias*****12 & 20,95 & 29,01 & 28,9 & 27,45 & 26,6 & & & & \\
\hline & & Taxa de & alongame & ento folia & $\operatorname{ar}(\mathrm{TALF}$ & $\left.\mathrm{mm} \mathrm{dia}{ }^{-1}\right)$ & & & \\
\hline & & Somb & ora $(\%)$ & & & & $\mathrm{P}^{*}$ & & \\
\hline Adubação & 0 & 30 & 50 & 70 & Média & Adub & b Somb & $\begin{array}{l}\text { Adub x } \\
\text { Somb }\end{array}$ & $(\%)$ \\
\hline Sem adubo $* * 13$ & 23,76 & 46,78 & 39,20 & 41,75 & 37,87 & & & & \\
\hline Com adubo $* * * 14$ & 29,84 & 48,90 & 48,90 & 37,38 & 41,25 & 0,41 & 0,014 & 0,67 & 25,24 \\
\hline Médias****15 & 26,80 & 47,84 & 44,05 & 39,42 & 39,56 & & & & \\
\hline & & Taxa d & e senescê & ncia folia & $\operatorname{ar}(\mathrm{TSF} n$ & $\left.n m \operatorname{dia}^{-1}\right)$ & & & \\
\hline & & Somb & ora (\%) & & & & $\mathrm{P}^{*}$ & & \\
\hline Adubação & 0 & 30 & 50 & 70 & Média & Adub & Somb & $\begin{array}{l}\text { Adub x } \\
\text { Somb }\end{array}$ & $(\%)$ \\
\hline Sem adubo $* * 16$ & 19,12 & 23,28 & 35,50 & 17,13 & 23,75 & & & & \\
\hline Com adubo $* * * 17$ & 21,22 & 16,83 & 16,83 & 16,69 & 17,89 & 0,24 & 0,60 & 0,45 & 55,87 \\
\hline Médias*****18 & 20,17 & 20,06 & 26,02 & 16,91 & 20,8 & & & & \\
\hline & & axa de al & ongament & to de colr & mo (TAL & $\mathrm{C} \mathrm{cm}$ dias & & & \\
\hline & & Sombra & $(\%)$ & & & & $\mathrm{P} *$ & & \\
\hline Adubação & 0 & 30 & 50 & 70 & Médias & Adub & Somb & $\begin{array}{l}\text { Adub x } \\
\text { Somb }\end{array}$ & $(\%)$ \\
\hline Sem adubo $* * 19$ & 0,61 & 0,61 &, 60 & 0,68 & $0,62^{\mathrm{B}}$ & & & & \\
\hline Com adubo $* * * 20$ & 0,63 & 0,95 &, 95 & 0,80 & $0,83^{\mathrm{A}}$ & 0,010 & 0,35 & 0,30 & 23,55 \\
\hline Médias****21 & 0,62 & 0,78 &, 77 & 0,74 & 0,72 & & & & \\
\hline & & & & locrono $\mathrm{d}$ & $\operatorname{dias}^{-1}$ & & & & \\
\hline$\Delta d u b$ & & Sombra & $(\%)$ & & & & $\mathrm{P}^{*}$ & & \\
\hline Aauoaçao & 0 & 30 & 50 & 70 & as & Adub & Somb & $\begin{array}{l}\text { Adub x } \\
\text { Somb }\end{array}$ & $(\%)$ \\
\hline
\end{tabular}


Rev. Bras. Saúde Prod. Anim., Salvador, v.15, n.4, p.994-1005 out./dez., 2014 http://www.rbspa.ufba.br ISSN 15199940

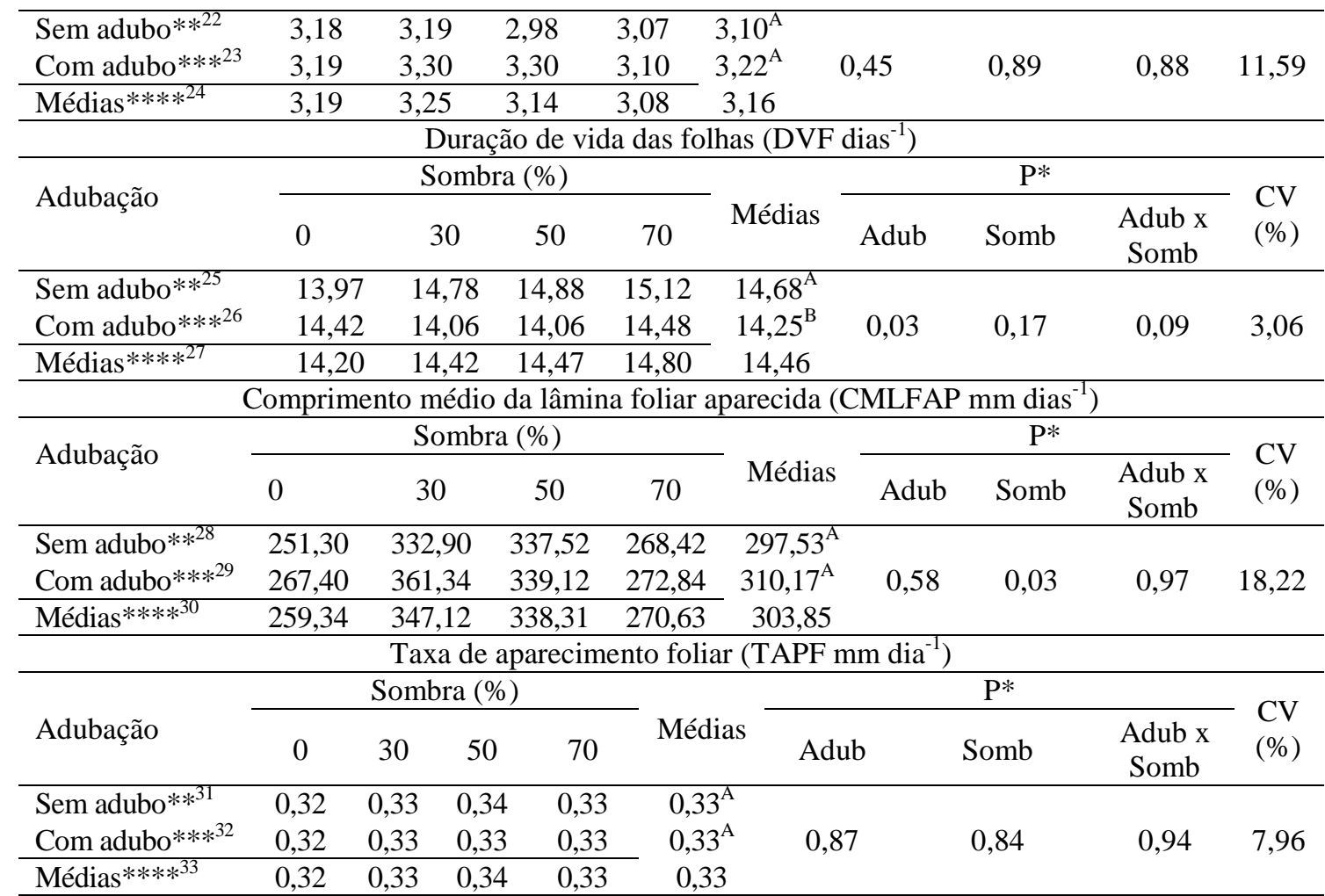

Médias seguidas por letras maiúsculas nas colunas diferentes para a mesma variável, diferem a 5\% de probabilidade de erro tipo 1 pelo teste t-Student.

*Probabilidade de erro tipo 1 pelo teste $\mathrm{F}$; ** equação referente ao efeito do sombreamento nas forragens sem adubo; *** equação referente ao efeito do sombreamento nas forragens com adubo; **** equação referente ao efeito do sombreamento nas forragens; $\mathbf{1}-\hat{\mathrm{Y}}=\mathrm{NS} ; \mathbf{2}-\hat{\mathrm{Y}}=\mathrm{NS} ; \mathbf{3}-\hat{\mathrm{Y}}=\mathrm{NS} ; \mathbf{4}-\hat{\mathrm{Y}}=\mathrm{NS} ; \mathbf{5}$ $\hat{\mathrm{Y}}=\mathrm{NS} ; \mathbf{6}-\hat{\mathrm{Y}}=\mathrm{NS} ; \mathbf{7}-\hat{\mathrm{Y}}=\mathrm{NS} ; \mathbf{8}-\hat{\mathrm{Y}}=\mathrm{NS} ; \mathbf{9}-\hat{\mathrm{Y}}=\mathrm{NS} ; \mathbf{1 0}-\hat{\mathrm{Y}}=\mathrm{NS} ; \mathbf{1 1}-\hat{\mathrm{Y}}=\mathrm{NS} ; \mathbf{1 2}-\hat{\mathrm{Y}}=21,05+$ $0,37 \mathrm{X}-0,0040 \mathrm{X}^{2}\left(\mathrm{R}^{2}=98,80\right) ; \mathbf{1 3}-\hat{\mathrm{Y}}=\mathrm{NS} ; \mathbf{1 4}-\hat{\mathrm{Y}}=\mathrm{NS} ; \mathbf{1 5}-\hat{\mathrm{Y}}=27,29+0,95 \mathrm{X}-0,1133 \mathrm{X}^{2}\left(\mathrm{R}^{2}=\right.$ 95,09); $16-\hat{\mathrm{Y}}=\mathrm{NS} ; \mathbf{1 7}-\hat{\mathrm{Y}}=\mathrm{NS} ; \mathbf{1 8}-\hat{\mathrm{Y}}=\mathrm{NS} ; \mathbf{1 9}-\hat{\mathrm{Y}}=\mathrm{NS} ; \mathbf{2 0}-\hat{\mathrm{Y}}=\mathrm{NS} ; \mathbf{2 1}-\hat{\mathrm{Y}}=\mathrm{NS} ; 22-\hat{\mathrm{Y}}=\mathrm{NS} ; 23$ - $\hat{\mathrm{Y}}=\mathrm{NS} ; 24-\hat{\mathrm{Y}}=\mathrm{NS} ; \mathbf{2 5}-\hat{\mathrm{Y}}=\mathrm{NS} ; \mathbf{2 6}-\hat{\mathrm{Y}}=\mathrm{NS} ; \mathbf{2 7}-\hat{\mathrm{Y}}=\mathrm{NS} ; \mathbf{2 8}-\hat{\mathrm{Y}}=\mathrm{NS} ; \mathbf{2 9}-\hat{\mathrm{Y}}=\mathrm{NS} ; \mathbf{3 0}-\hat{\mathrm{Y}}=$ $259,16+5,05 X-0,070 X^{2}\left(R^{2}=99,97\right) ; 31-\hat{Y}=N S ; 32-\hat{Y}=N S ; 33-\hat{Y}=N S$.

Em condições de sombreamento, é possível observar ainda um maior desenvolvimento da parte aérea para aumentar a competitividade e eficiência na fixação de $\mathrm{CO}_{2}$. De acordo Valladares et al. (2007), essa característica recebe $\mathrm{o}$ nome de plasticidade fenotípica que, segundo esses mesmos autores, é a capacidade de determinado genótipo apresentar diferentes fenótipos sob diferentes condições ambientais. Tais autores, ainda enfatizaram que os vegetais têm capacidade de apresentar esses recursos para diferentes atributos fisiológicos, morfológicos e anatômicos, incluindo ainda mudanças na reprodução e desenvolvimento. Sendo assim, um maior alongamento de colmo nos tratamentos que receberam sombra é um dos mecanismos adaptativos do vegetal sobre sua nova condição de manejo.

A taxa de alongamento foliar (TALF), embora não tenha apresentado interação entre os fatores, para o sombreamento foi significativo $(\mathrm{P}<0,05)$, embora se esperasse que as plantas que receberam adubação apresentariam maiores médias de TALF, mas isso não foi constatado, uma vez que a aplicação $80 \mathrm{~kg}$ de $\mathrm{N}$ ha . ano $^{-1}$ ser considerada baixa, isso reduziu as respostas de maiores médias de alongamento foliar da planta, provavelmente aplicações acima de 50 
$\mathrm{kg}$. ha ${ }^{-1}$ por corte da planta, que permitiria respostas consideráveis de alongamento foliar. De acordo Teixeira et al. (2005), no vegetal em condições nutricionais favoráveis, o transporte de nutrientes produzidos na fotossíntese é disponibilizado principalmente ao meristema apical, folhas emergentes e folhas em expansão, favorecendo assim o alongamento das folhas. Sendo estas, influenciadas diretamente pelo sombreamento, que possibilitou maiores taxas de alongamento, isso pode estar associado à necessidade que a planta tem de captar luz em situações com baixa incidência solar.

$\mathrm{O}$ sombreamento ainda possibilitou um aumento nas CB, TALF e, consequentemente, no CMLFAP, quando se tem um alongamento de colmo e, por sua vez, de bainha. As folhas tendem a crescer mais para saírem de dentro do cartucho, desse modo, já iniciam sua expansão em um tamanho maior, acarretando assim um maior alongamento foliar, em outras palavras, o maior comprimento de bainha força um maior comprimento de folha para expansão e, consequentemente, um maior comprimento de folhas expandidas.

$\mathrm{O}$ fato de não ter ocorrido diferenças $(\mathrm{P}>0,05)$ entre os tratamentos adubados e os sem adubação na TALF, pode estar associado à matéria orgânica residual no solo que vai sendo decomposta ao longo do tempo e fornecendo nitrogênio para absorção via raiz, pois o ensaio foi alocado em uma pastagem já implantada há dois anos, mesmo que se tenha realizado todo o protocolo de corte de estabilização e remoção do material remanescente, pois a retirada dos materiais em decomposição e materiais decompostos torna-se inviável, podendo ter influenciado na resposta final. No entanto, é importante ressaltar que esse fenômeno é menos comum em Neossolos Quatzarênicos por este proporcionar uma alta taxa de degradação e baixa deposição de matéria orgânica (ARAÚJO et al., 2011).

Quanto à TSF, foi realizada uma transformação dos dados $(\log (x+1))$, já que por esta variável não se mostrou normal à luz do teste de normalidade. Após a transformação, não se constatou diferenças significativas $(\mathrm{P}>0,05)$ para adubação e para sombreamento artificial e nem a interação foi constatada. Oliveira et al. (2005), afirma que a aplicação de um conjunto de nutrientes possibilita influência na redução TSF, enquanto que a utilização de elementos separados para adubação pode não exercer nenhuma influência na alteração desta variável. Esse resultado corrobora com os resultados encontrados por Martuscello et al. (2009), que trabalhando em Latossolo Vermelho Distrófico, com três gêneros de Brachiaria decumbens, B. brizantha cv. Marandu e Xaraéz, com sombreamento artificial de 50 e $70 \%$, e cortes a $20 \mathrm{~cm}$ do solo não constatou efeito da sombra sobre a senescência foliar.

Para o filocrono, no presente ensaio, não foi constatada significância para os efeitos dos fatores estudados e para interação entre estes, sendo o valor médio de filocrono igual a 3,16 dias. $\mathrm{O}$ filocrono está associado ao comprimento médio de lâmina foliar aparecida (CMLFaP), que sofreu influencia pela redução no nível de disponibilidade de luz ao dossel $(\mathrm{P} \leq$ 0,03), com um valor médio de 303,85 $\mathrm{mm} \cdot \mathrm{dia}^{-1}$ e uma taxa de aparecimento foliar (TAPF), que não foi significativo para nenhum dos tratamentos e não ocorreu interação. Essas variáveis são influenciadas ainda pela disponibilidade de sol intenso disponível para o vegetal, porém, em muitas fases do dia, essa disponibilidade de luz possibilita 
espectro de fótons para absorção de luz, acelerando o crescimento pela produção intensa de fotoassimilados. Resultado semelhante ao encontrado por Paciullo et al. (2008), esse valor de filocrono de 3,16 do presente ensaio está bem abaixo dos valores encontrados por Alexandrino et al. (2004), avaliando o filocrono em $B$. brizantha, verificaram que, com o aumento das doses de nitrogênio, o filocrono reduziu de 12,2 para 6,99 dias, respectivamente, nas plantas adubadas com 0 a $40 \mathrm{mg} \cdot \mathrm{dm}^{-3}$ de N. Dessa forma, pode se ter uma maior quantidade de colheitas e se reduzir as perdas por morte de folhas por ciclo.

Em relação à DVF, a interação não foi significativa $(\mathrm{P}>0,05)$. Nos tratamentos adubados, as médias foram inferiores em comparação àquelas sem adubação 14,25 e 14,68 dias de DVF, para adubada e sem adubação, respectivamente, ou seja, quando ocorre a inclusão da adubação, ocorre uma redução da DVF. Esse efeito está ligado à capacidade fenotípica que o vegetal tem de se adaptar sobre situações de estresse. (ZEFERINO, 2006) Em uma situação estressante por falta de luminosidade favorável e falta de nutriente via adubação, as folhas tendem a durarem mais e assim garantirem a atividade fotossintética alta, pois folhas jovens são drenos, em outras palavras, estas necessitam mais de fotoassimilados deslocados do que produzem produtos fotossintéticos. O problema é que folhas mais velhas tendem a apresentar um maior teor de lignificação na parede celular, podendo ser menos degradável no rúmen.

A TAPF, não foi alterada em nenhum dos tratamentos, sendo eles com adubação ou sem adubação. Esse comportamento já era esperado, uma vez que estudos relatam que alterações nas características morfogênicas bem como na TAPF têm ocorrido no período de escassez de chuvas onde o sombreamento possibilita uma maior umidade do solo, favorecendo o aumento da TAPF (CASTRO et al., 1999; MARTUSCELLO et al., 2009), no entanto, tal aspecto parece não ocorrer em condições de bom suprimento hídrico como no caso deste ensaio.

O número de perfilhos não foi alterado $(\mathrm{P}>0,05)$ pelos tratamentos sendo que, com a presença do sombreamento, o vegetal não deixou de investir em comunidades de perfilhos para investir em indivíduos, uma vez que o que é produzido de fotoassimilados é deslocado para as partições do vegetal como colmo e bainha e não para estimular o perfilhamento (Tabela 3). Embora o esperado fosse que a adubação e luminosidade estimulassem o surgimento de novos perfilhos, não foi constatado este comportamento no presente ensaio.

O sombreamento traz como resultado uma baixa quantidade de luz sobre as gemas que originam novos perfilhos e permite, ainda, uma grande variação no comprimento de ondas fotossintéticas, que compreende de vermelho a vermelho extremo que está intimamente ligada à qualidade da luz que chega às zonas basilares a ponto de estimular o perfilhamento. (FRANK \& HOFMAN, 1994).

Em nenhuma das características agronômicas estudadas ocorreu interação $(\mathrm{P}>0,05)$, porém os tratamentos com sombra influenciaram na resposta de percentual de MS, embora tenha ocorrido uma queda na produção durante os ciclos estudados para esta variável. Já para as demais (kg de MS . ha ${ }^{-1}$ e NPERF. ha ${ }^{-1}$ ), não se evidenciou diferença significativa ( $\mathrm{P}>0,05)$, sendo que se esperava que os tratamentos com até $30 \%$ de sombra seriam os que apresentariam médias, 
aproximadas ao do sol pleno, os três ciclos estudados não foram suficientes para comprovar essa diferenciação. Talvez o fato de o sombreamento não afetar produção de matéria seca aconteceu em virtude do incremento de colmo que ocorreu na planta durante o ensaio, provavelmente, em longo prazo, os sombreamentos mais intensos poderiam reduzir da produção.

Tabela 3. Componentes agronômicos da forrageira Urochloa brizantha cv. Marandu

\begin{tabular}{|c|c|c|c|c|c|c|c|c|c|}
\hline \multicolumn{10}{|c|}{ Número de perfilho (NPERF $\mathrm{m}^{-2}$ ) } \\
\hline \multirow[b]{2}{*}{ Adubação } & \multicolumn{4}{|c|}{ Sombra $(\%)$} & \multirow[b]{2}{*}{ Médias } & \multicolumn{3}{|c|}{$\mathrm{P} *$} & \multirow{2}{*}{$\begin{array}{l}\text { CV } \\
(\%)\end{array}$} \\
\hline & 0 & 30 & 50 & 70 & & Adub & Somb & $\begin{array}{c}\text { Adub x } \\
\text { Somb }\end{array}$ & \\
\hline Sem adubo***1 & 588,80 & 612,20 & 486,34 & 493,43 & $545,19^{\mathrm{A}}$ & \multirow{3}{*}{0,49} & \multirow{3}{*}{0,39} & \multirow{3}{*}{0,55} & \multirow{3}{*}{$\begin{array}{c}18,7 \\
9\end{array}$} \\
\hline Com adubo $* * *^{2}$ & 605,18 & 570,06 & 619,22 & 507,06 & $575,38^{\mathrm{A}}$ & & & & \\
\hline Médias $* * * * 3$ & 596,98 & 591,13 & 552,78 & 500,24 & 560,28 & & & & \\
\hline \multicolumn{10}{|c|}{ Percentual de matéria seca (MS \%) } \\
\hline \multirow[b]{2}{*}{ Adubação } & \multicolumn{4}{|c|}{ Sombra $(\%)$} & \multirow[b]{2}{*}{ Médias } & \multicolumn{3}{|c|}{$\mathrm{P}^{*}$} & \multirow{2}{*}{$\begin{array}{l}\text { CV } \\
(\%)\end{array}$} \\
\hline & 0 & 30 & 50 & 70 & & Adub & Somb & $\begin{array}{l}\text { Adub x } \\
\text { Somb }\end{array}$ & \\
\hline Sem adubo $* *^{4}$ & 26,09 & 20,04 & 23,47 & 24,49 & $23,52^{\mathrm{A}}$ & \multirow{3}{*}{0,17} & \multirow{3}{*}{0,03} & \multirow{3}{*}{0,66} & \multirow{3}{*}{$\begin{array}{c}11,3 \\
4\end{array}$} \\
\hline Com adubo $* * * 5$ & 24,60 & 20,52 & 21,59 & 21,24 & $21,98^{\mathrm{A}}$ & & & & \\
\hline Médias $* * * * 6$ & 25,33 & 20,28 & 22,53 & 22,86 & 22,75 & & & & \\
\hline \multicolumn{10}{|c|}{ Qilograma de matéria seca por hectare $\left(\mathrm{Kg}\right.$ de $\left.\mathrm{MS} \mathrm{ha}^{-1}\right)$} \\
\hline \multirow[b]{2}{*}{ Adubação } & \multicolumn{4}{|c|}{ Sombra $(\%)$} & \multirow[b]{2}{*}{ Médias } & \multicolumn{3}{|c|}{$\mathrm{P}^{*}$} & \multirow{2}{*}{$\begin{array}{l}\mathrm{CV} \\
(\%)\end{array}$} \\
\hline & 0 & 30 & 50 & 70 & & Adub & Somb & $\begin{array}{c}\text { Adub x } \\
\text { Somb }\end{array}$ & \\
\hline Sem adubo**7 & 3758,70 & 3908,17 & 3104,66 & 3149,95 & $3480,37^{\mathrm{A}}$ & & & & \\
\hline Com adubo $* * * 8$ & 3863,33 & 3639,15 & 3952,98 & 3236,93 & $3673,10^{\mathrm{A}}$ & 0,49 & 0,39 & 0,55 & 18,79 \\
\hline Médias****9 & 3811,01 & 3773,67 & 3528,82 & 3193,44 & 3576,73 & & & & \\
\hline
\end{tabular}

Médias seguidas por letras maiúsculas nas colunas diferentes para a mesma variável, diferem a $5 \%$ de probabilidade de erro tipo 1 pelo teste t-Student. * probabilidade de erro tipo 1 pelo teste $\mathrm{F}$.** equação referente ao efeito do sombreamento nas forragens sem adubo; *** equação referente ao efeito do sombreamento nas forragens com adubo; **** equação referente ao efeito do sombreamento nas forragens; $1-\hat{\mathrm{Y}}=\mathrm{NS} ; \mathbf{2}-\hat{\mathrm{Y}}=\mathrm{NS} ; \mathbf{3}-\hat{\mathrm{Y}}=\mathrm{NS} ; \mathbf{4}-\hat{\mathrm{Y}}=\mathrm{NS} ; \mathbf{5}-\hat{\mathrm{Y}}=\mathrm{NS} ; \mathbf{6}-\hat{\mathrm{Y}}=25,20-0,20 \mathrm{X}+$ $0,0025 \mathrm{X}^{2}\left(\mathrm{R}^{2}=78,05\right) ; \mathbf{7}-\hat{\mathrm{Y}}=\mathrm{NS} ; \mathbf{8}-\hat{\mathrm{Y}}=\mathrm{NS} ; \mathbf{9}-\hat{\mathrm{Y}}=\mathrm{NS}$.

Outro fator que pode ter influenciado na resposta para essa variável é que a gramínea em sistema sombreado tende alocar fotoassimilados para o perfilho em detrimento à raiz; esse maior favorecimento acarreta em um aumento no peso da massa por perfilho, podendo influenciar na resposta de produção de MS (PACIULLO et al., 2008). O mesmo autor, em seu trabalho com sombreamento, concluiu que a falta de produção de perfilhos é compensada pelo alongamento de colmo nos níveis de sombreamento mais intenso.

Segundo Sbrissia \& Da Silva (2001), as gramíneas com perfilhos mais pesados tendem a diminuir sua população e as plantas com perfilhos mais leves tem um aumento considerável em quantidade. Isso reforça a capacidade de adaptação das plantas, embora as plantas de ciclo $\mathrm{C}_{4}$ tenham uma redução na produção de matéria seca com o sombreamento. (MARTUCELLO et al., 2009) A preconização de alocar 
produtos oriundos da fotossíntese permite o vigor maior do perfilho, e um peso superior reduzindo o impacto na produção de MS, embora a raiz seja prejudicada por esse processo o mesmo garante a perenidade do vegetal, mesmo que se torne sensível à situações de estresse elevado por falta de água por apresentarem raízes mais superficiais.

A Urochloa brizantha cv. Marandu mostrou capacidade de adaptação aos níveis crescentes de sombreamento, sendo capaz de produzir um percentual de MS considerável em comparação ao sol pleno. $\mathrm{O}$ sombreamento conferiu maiores TALC, reduziu o numero de perfilhos. $\mathrm{m}^{-2}$, e apresentou o maior percentual de folhas vivas no perfilho $\mathrm{O}$ sombreamento com $50 \%$ de sombra e adubado teve produção de MS aproximada com o tratamento em sol pleno, conferido pelo aumento no comprimento de bainha, possivelmente, pela produção perfilhos mais pesados.

\section{REFERÊNCIAS}

\author{
ALEXANDRINO, E.; NASCIMENTO \\ JUNIOR, D.; MOSQUIM, P.R; \\ REGAZZI, A.J.; ROCHA F.C. \\ Características morfogênicas e \\ estruturais na rebrotação da Brachiaria \\ brizantha $\mathrm{cv}$. Marandu submetida a três \\ doses de nitrogênio. Revista Brasileira \\ de Zootecnia, v.33, n.6, p.1372-1379, \\ 2004.
}

ARAÚJO, A.S; SANTOS, A.C; SANTOS MAIA, P; CAVALCANTE SILVA; J.E; DONIZETTI, J.G; Produtividade do capim-marandu e alterações químicas do solo submetido a doses de dejetos líquidos de bovinos.

Revista de Ciências Agrárias, v.54, n.3 p.235-246, 2011.
BARBOSA, R.A.; NASCIMENTO

JUNIOR, D.; EUCLIDES, V.P.B.; REGAZZI, A.J; FONSECA, D.M.

Características morfogênicas e acúmulo de forragem do Capim-Tanzânia (Panicum maximum Jacq. cv. Tanzânia) em dois resíduos forrageiros póspastejo. Revista Brasileira de Zootecnia, v.31, n.2, p.583-593, 2002.

BARTLETT, M.S. Properties of sufficiency and statistical tests. Proceedings of the Royal Statistical Society, v.160, n.901, p.268-282, 1937.

CASTRO, C.R.T.; GARCIA, R.; CARVALHO, M.M.; COUTO, L. Produção forrageira de gramíneas cultivadas sob luminosidade reduzida. Revista Brasileira de Zootecnia, v.28, n.28, p.919-927, 1999.

COCHRAN, W.G. The distribution of the largest of a set of estimated variances as a fraction of their total.

Annals of Human Genetics, v.11, n.1, p.47-52, 1941.

EMPRESA BRASILEIRA DE
PESQUISA AGROPECUÁRIA -
EMBRAPA. Centro Nacional e Pesquisa em Solos. Sistema Brasileiro de Classificação de Solos. Brasilia/Rio de Janeiro, 2006. 306p.

FRANK, A.B.; HOFMAN, L. Light quality and stem numbers in coolseason forage grasses. Crop Science, v.34, n.2, p.468- 473, 1994.

LAMAIRE, G.; CHAPMAN, D. Tissue flows in grazed plant communities. In: HODGSON, J.; ILLIUS, A.W. (Eds.)

The ecology and management of grazing systems. Wallingford: $\mathrm{CAB}$ International, 1996. p.3-36. 
Rev. Bras. Saúde Prod. Anim., Salvador, v.15, n.4, p.994-1005 out./dez., 2014 http://www.rbspa.ufba.br ISSN 15199940

MARTUSCELLO, J.A.; JANK, L.; GONTIJO NETO, M.M.; LAURA, A.L.; CUNHA, N.F.V. Produção de gramíneas do gênero Brachiaria sob níveis de sombreamento. Revista Brasileira de Zootecnia, v.38, n.7, p.1183-1190, 2009.

MOREIRA, G.R.; SALIBA, E.O.S.; MAURÍCIO, R.M.; SOUSA, L.F.; FIGUEIREDO, M.P; GONÇALVES, L.C.; RODRIGUEZ, N.M. Avaliação da Brachiaria brizantha cv. Marandu em sistemas silvipastoris. Arquivo

Brasileiro de Medicina Veterinária e Zootecnia, v. 61, n.3, p.706-713, 2009.

PACIULLO, D.S.C.; CARVALHO, C.A.B.; AROEIRA, L.J.M.; MORENZ, M.F.; LOPES, F.C.F.; ROSSIELLO, R.O.P. Crescimento de capimbraquiária influenciado pelo grau de sombreamento e pela estação do ano. Pesquisa Agropecuária Brasileira, v.43, n.7, p.917- 923, 2008.

OLIVEIRA, P.P.A.; TRIVELIN, P.C.O.; OLIVEIRA, W.S.; CORSI, M. Fertilização com $\mathrm{N}$ e $\mathrm{S}$ na recuperação de pastagem de Brachiaria brizantha cv. Marandu em Neossolo Quartzarênico.

Revista Brasileira de Zootecnia, v.34, n.4, p.1121-1129, 2005.

PAGIOLA, S.; AGOSTINI, P.; GOBBI, J.; DE HAAN, C.; IBRAHIM, M.; MURGUEITIO, E.; RAMIREZ, E.; ROSALES, M.; RUIZ, J.P. Payng for Biodiversity consevatian services. Washington: Word Bank, 2004. (Woerd Bank Envioronmental as Economic Series, 96)

SANTOS, M.E.R.; FONSECA, D.M.; BRAZ SANTOS, T.G.; SILVA, G.P.; GOMES, V.M.; SILVA, S.P. Influência da localização das fezes nas características morfogênicas e estruturais e no acúmulo de forragem em pastos de capim-braquiária. Revista Brasileira de Zootecnia, v.40, n.1, p.31-38, 2011.

SBRISSIA, A.F.; Da SILVA, S.C. O ecossistema de pastagens e a produção animal. In: REUNIÃO ANUAL DA SOCIEDADE BRASILEIRA DE ZOOTECNIA, 38., 2001, Piracicaba. Anais... Piracicaba: Sociedade Brasileira de Zootecnia, 2001. p. 733754.

SHAPIRO, S.S.; WILK, M. B. An analysis of variance for normality (Complete samples). Biometrika, v.52, n.3/4, p.591-611, 1965.

TEIXEIRA, A.C.B.; GOMIDE, J.A.; OLIVEIRA, J.A.; ALEXANDRINO, E.; LANZA, D.C.F. Distribuição de fotoassimilados de folhas do topo e da base do capim Mombaça (Panicum maximum Jacq.) em dois estágios de desenvolvimento. Revista Brasileira de Zootecnia, v.34, n.2, p.479-488, 2005.

VALLADARES, F.; GIANOLI, E.; GOMEZ, J.M. "Ecological limits to plant phenotypic plasticity," New Phytologist, v.176, n.4, p.749-763, 2007.

ZEFERINO, C.V. Morfogênese e dinâmica do acúmulo de forragem em pastos de capim-marandu [Brachiaria brizantha (Hochst. ex A. Rich) cv. Marandu] submetidos a regimes de lotação intermitente por bovinos de corte. 2006. 193f. Dissertação (Mestrado) - Escola Superior de Agricultura Luiz de Queiroz, Universidade de São Paulo, Piracicaba.

Data de recebimento: 29/09/2014

Data de aprovação: 01/12/2014 